\title{
Healthcare seeking behaviour among female garment workers in Koggala Free Trade Zone, Sri Lanka
}

\author{
Sanjeeva Rajapakse ${ }^{1 *}$, Frances Morin ${ }^{1}$, Truls Østbye ${ }^{2}$, Vijitha De Silva ${ }^{3}$ \\ ${ }^{1}$ University of British Columbia, Canada; ${ }^{2}$ Duke University, USA; ${ }^{3}$ University of Ruhuna, Sri Lanka \\ *Correspondence: sanjeeva.rajapakse@ mail.mcgill.ca
}

DOI: https://doi.org/10.4038/jccpsl.v24i4.8159

Received on: 12 June 2018

Accepted on: 03 October 2018

\begin{abstract}
Background: In a 2011 study, the prevalence of musculoskeletal disease among a female garment worker group in Koggala Free Trade Zone (Sri Lanka) was estimated to be $15.5 \%$. Nearly all affected women in this group felt their problems disrupted their leisure activities and household work, while only a few reported missing work as direct consequences of their discomfort. The reason why they did not seek treatment or take leave, however, was not clear.

Objective: To explore the healthcare seeking behaviour and barriers that prevent female workers at Koggala Free Trade Zone from seeking care

Methods: This is an exploratory mixed methods quantitative-qualitative study utilizing pre-interview questionnaires and focus group discussions. Four focus group discussions were held, each consisting of 6 female garment workers $(n=24)$. Discussions were transcribed and processed through three levels of analysis and qualitative coding. Major themes on healthcare seeking and barriers to healthcare were identified using the resulting codebook.

Results: The quantitative data showed that more than $90 \%$ of focus group participants $(\mathrm{n}=22)$ reported musculoskeletal pain in the month prior to the study and less than $30 \%$ sought care. Major barriers to healthcare seeking were identified: workers' perception on Western medical treatment and pain, the difficulty in accessing healthcare outside the factory, pressure from management to reach production goals, and financial and personal factors from taking time off work.

Conclusions: Multiple factors play a role in healthcare seeking among Sri Lankan female garment workers. Targeted occupational health interventions should focus on alleviating these pain points for garment workers and on educating workers and factory management on the benefits of proactive healthcare seeking behaviour for Sri Lankan female garment workers.
\end{abstract}

Key words: occupational health, musculoskeletal disease, female garment workers, healthcare seeking behaviour, barriers to healthcare 


\section{Introduction}

Free trade zones (FTZ) are customs-free, taxexempt manufacturing facilities in Sri Lanka that were created to spur foreign investments in response to unemployment rates in the 1960's and 1970's (1). The number of FTZs in Sri Lanka grew over time from its inception in 1977 and they now employ 408,000 workers, $88 \%$ of which are women (2). While there have been great strides in reducing unemployment in Sri Lanka, there are still concerns regarding the working and health conditions within the FTZs (3).

Previous research by a joint team from Duke and Ruhuna University (4) on a group of female garment factory workers within the Koggala FTZ identified musculoskeletal pain, accidents, respiratory complaints, skin problems, headache and mental health as occupational health problems among workers. Overall, musculoskeletal problems were reported by $15.5 \%$ of the worker group $(n=164 / 1058)$. Although most participants $(90 \%)$ experiencing musculoskeletal pain reported that their injuries were highly disruptive to their work and quality of life, only a few actually reported missing work to seek treatment or take sick leave $(0.0-20.0 \%)$. The reasons why these workers did not seek treatment are yet to be elucidated. It has been suggested in previous research that Sri Lankan workers who do not complete enough work or are absent due to illness are at risk of losing their job or suffering financial penalties (5). Sri Lankan factory workers report that they fear that their jobs are transient and that they can be easily replaced by other workers (6). Anthropologists have also suggested that Sri Lankan female workers play into an obedient "good girl" persona, one that is afraid of offending management and losing their jobs (7).

The objective of this paper was to follow-up on the Duke-Ruhuna study and identify the factors that influence healthcare seeking for musculoskeletal pain among female garment factory workers within the Koggala FTZ. Through this research, we hope to provide insights to public health officials and factory owners to help reduce the healthcare barriers for Sri Lankan female garment workers.

\section{Methods}

This project is an exploratory mixed methods quantitative-qualitative study, using pre-interview paper questionnaires and focus group discussions. Four focus group discussions were held, each consisting of 6 female garment workers $(n=24)$. The focus groups were led by a moderator in a semi-structured format with open discussion around eight focus guide questions. The protocol was approved by the Ethics Review Committee of the Faculty of Medicine, University of Ruhuna and the University of British Columbia Behavioural Research Ethics Board.

Female workers who were above the age of 18 , had been employed in the textile industry in Koggala FTZ for a minimum period of six months and were able to carry on a conversation at a grade eight level in either Sinhala or English were considered eligible to participate in this study. Such participants were recruited from one women's hostel within the Koggala FTZ, where multiple factories house their workers. Specific factories were not identified, and participants did not reveal which factory they worked at. The Ethics Review Boards originally approved participants to be reimbursed for transport and child care up to Rs. 1000. However, these expectations changed in the field and it was decided that all participants be compensated Rs. 1000 for their time, which was the local norm for similar international studies.

Prior to the focus group discussions, an anonymous paper questionnaire was administered to collect background information from each participant. Data were collected on age, role at the factory, length of stay at the factory, education, home town, family status and salary. An experienced facilitator fluent in both Sinhala and English languages, along with two members of the research team conducted the focus groups using a semi-structured format with group discussion around open-ended questions. Participants were encouraged to share their perceptions of 1) health problems experienced and 2) observed in the workplace, 3) barriers to healthcare seeking behaviour among participants and 4) perceived expectations (from a manager, family or self) of participants.

Focus group discussions were audio-recorded. A Sri Lankan professional translated the audio-recordings from Sinhala to English and transcribed the focus group discussions. In the first cycle of analysis, two researchers independently coded the first focus group transcript, and then compared codes and generated a codebook, identifying major themes on healthcare seeking. In the second cycle of analysis, the first focus group was re-coded and the remaining three focus groups were coded using the codebook. During the third cycle of analysis, transcript segments were grouped by major themes and provided qualitative evidence of healthcare seeking behaviour. 


\section{Results}

The average age of the 24 female participants in the study was 26.6 years $(\mathrm{SD}=8.0)$. On average, they had been working for 43.4 months $(\mathrm{SD}=36.6)$. As shown in Table 1, the most common factory position was machine operator $(58.3 \%)$ followed by quality control (20.8\%), packing section (16.7\%) and team lead (4.2\%). Most participants had General Certificate

Table 1. Characteristics of the participants

\begin{tabular}{|c|c|}
\hline Characteristic & No. $(\%)$ \\
\hline \multicolumn{2}{|l|}{ Age (years) } \\
\hline Less than 20 & $5(21.7)$ \\
\hline $20-24$ & $7(30.4)$ \\
\hline $25-29$ & $4(17.4)$ \\
\hline $30-34$ & $4(17.4)$ \\
\hline 35 and above & $3(12.9)$ \\
\hline \multicolumn{2}{|l|}{ Position } \\
\hline Quality control & $5(20.8)$ \\
\hline Machine operator & $14(58.3)$ \\
\hline Team lead & $1(4.2)$ \\
\hline Packing section & $4(16.7)$ \\
\hline \multicolumn{2}{|l|}{ Education ${ }^{1}$} \\
\hline Grade 10 or below & $1(4.2)$ \\
\hline GCE Ordinary Level & $15(62.5)$ \\
\hline GCE Advanced Level and above & $8(33.3)$ \\
\hline \multicolumn{2}{|c|}{ Population size of the home town/village } \\
\hline Less than 20,000 & $12(50)$ \\
\hline $20,000-49,999$ & $2(8.3)$ \\
\hline $50,000-69,999$ & $5(20.8)$ \\
\hline 70,000 and above & $5(20.8)$ \\
\hline \multicolumn{2}{|l|}{ Children } \\
\hline Yes & $1(4.2)$ \\
\hline No & $23(95.8)$ \\
\hline \multicolumn{2}{|l|}{ Time working in industry (months) } \\
\hline$<12$ & $5(20.8)$ \\
\hline $12-24$ & $5(20.8)$ \\
\hline $25-36$ & $4(16.7)$ \\
\hline$>36$ & $10(41.7)$ \\
\hline \multicolumn{2}{|l|}{ Reported monthly income (Rs.) } \\
\hline $16,000-17,999$ & $4(16.7)$ \\
\hline 18,000 & $15(62.5)$ \\
\hline $18,001-20,000$ & $4(16.7)$ \\
\hline$>20,000$ & $1(4.2)$ \\
\hline \multicolumn{2}{|l|}{ Does this salary meet your needs? } \\
\hline Yes & $7(29.2)$ \\
\hline No & $17(70.8)$ \\
\hline \multicolumn{2}{|l|}{ Pregnancy status } \\
\hline Pregnant & $0(0.0)$ \\
\hline Not pregnant & $23(95.8)$ \\
\hline Do not know/ No response & $1(4.2)$ \\
\hline
\end{tabular}

${ }^{1}$ General Certificate of Education 
of Education (GCE) Ordinary Level education (62.5\%), with a few having GCE Advanced Level education (33.3\%) and one having grade 10 or below education. Half of the participants were from towns smaller than 20,000 people, while the other half were from larger towns of various sizes. Only one participant reported having children. Almost $60 \%$ of the participants reported to have been working in the garment industry for less than 36 months at the time of the study. The average monthly income of study participants was Rs. 18,425 (approximately USD 121) from all sources, with $70 \%$ of participants reporting that this salary does not meet their needs. All participants sent remittances back home to their families.

Participants in all four focus groups reported access to healthcare professionals within the factory. Every participant interviewed reported having a clinic within their factory, with nurses available each week day. Each factory varies in the frequency of doctor visits, from at least one doctor visit a week to three. Participants reported that no formal training regarding work safety or occupational health is given at the factories.

To receive care within each factory setting, a certain work flow must be followed. If a worker has only a minor ailment, such as a cough or cold, they are allowed to go to the factory's sick room and take a break (approximately 15 minutes). For a headache or back pain, they may get 15-30-minute break. If there is a more serious health problem, the worker must first inform the work line's team leader about the issue. The team leader will then take the worker to the nurse in the factory's medical clinic. If the issue is critical, it would be brought up with management and the worker's family. The worker may then be sent to a government hospital, if necessary.

More than $90 \%$ of the focus group participants $(n=22)$ stated that they have suffered from "body pain" (musculoskeletal pain) in the past month. The severity of musculoskeletal pain was not reported. Despite having access to trained doctors and nurses, participants reported seeking care infrequently. Less than $30 \%$ of the participants reported going to the factory's clinic in the past month. When reasons for not seeking treatment were investigated, five major themes were discovered: 1) futility of treatment, 2) the preference for healthcare outside the factory, 3) pressure from management, 4) financial factors 5) and personal goals.

\section{Futility of treatment}

Participants in each focus group felt that musculoskeletal pain was not a sufficient reason to seek help from a nurse or doctor. Pain is mostly managed with over-the-counter medication and/or Ayurveda and herbal medicine, and medication from a healthcare professional is not seen as any more effective. Due to its chronicity, pain was not identified as a new issue either and did not warrant going to the doctor for further follow-up or re-assessment. It is also recognized as part of the job and cannot be avoided. Interestingly, for one participant, musculoskeletal pain was seen as transient.

"Back and leg pains are the most critical occupational health problems we have. We get pain mainly during work. Otherwise, we have no problems. For example, we have no pains when we are at home". (FG 4)

\section{Preference for healthcare outside the factory}

While healthcare in the factory is free, the doctors and factories do not cover the cost of pharmaceuticals for the workers. The workers themselves must go to the pharmacy and purchase their own medicine. While participants did not cite the cost of medication as a deterrent, they found it easier to seek help from a doctor outside, where they can also access a pharmacy at the same time.

Workers in general prefer to go to a doctor outside the factory for their medical problems. They report feeling more comfortable with an outside doctor, finding it better of having the choice of a doctor, and an overall better experience seeking help from outside as well. However, these doctors are not as readily available as the factory doctors, and one must take time off from work to seek treatment as there are no state-run hospitals or dispensaries near or in the zone.

\section{Target pressure from managers}

In each focus group discussion, the pressure to meet production targets set by management was a major theme discussed. The target system was reported to cause psychological impacts, including stress and depression as well as negative physical impacts on health, including difficulty sleeping and headaches. Finally, this system creates a working environment in which workers have a limited opportunity to take lunch 
breaks, go to the bathroom or seek medical attention, in fear of not reaching production targets.

"We get blamed when we go to sick room. We are normally allowed to stay there only for 10 minutes (allowed 15-30 minutes*) and the management forces us to get back to work...The management has little interest in our health". (FG 3)

When asked about expectations from the management, one discussion group responded;

"We are given targets that are unrealistic and hard to achieve. It is difficult to meet those targets... We are often blamed for not meeting the targets. We reduce our breaks and free times to meet the target”. (FG 3)

\section{Financial reasons for taking leave}

Workers at the factories get 14 days of paid leave each year. This leave includes medical leave, personal leave and vacation. However, if a worker gets a communicable disease, then they receive additional days off in addition to the 14 days. For example, for an eye infection, one gets three more days, for chickenpox they receive 21 more days, etc. Additionally, if one gets into a workplace accident, then she may receive additional leave. Any additional days taken after 14 days are deducted from their pay.

Workers feel an indirect pressure from management to not take medical leave, as if one worker is absent, the target bonus that all the other workers in her line would receive will be reduced, even if the line meets the target.

"If we get sick, our attendance bonus is cut. Each line has a daily target. If a worker in a line is absent due to sickness or other reason, the target bonus is reduced for all workers in that line even if the line meets the target”. (FG 3)

Since factory workers have a low baseline salary and are not paid during additional leave days, missing work due to a medical condition can have a serious impact on a worker's financial stability.

"It is sad when you think of it. Our salaries are low. We all feel like that. If we get sick, if there are no leave days left then the salary gets cut. I took 10 days extra leave and lost Rs. 8000 from salary. My basic salary was Rs. 16,500. So, it is a big cut”. (FG 1)
Moreover, participants disclosed that they could be compensated and receive bonuses for any unused leave days. Participants in the first focus group discussion reported that the management would as well provide awards, such as money, certificates and trophies for hard work. There are, therefore, negative and positive reinforcement tactics which encourage factory workers to work rather than take sick days off.

\section{Personal goals}

In addition to the pressure to meet the management's target, workers also have their own ambitions to make enough money to support their goals. Common reasons for work included gaining financial independence, supporting family members, funding future ambitions, while other participants were saving for higher education, collecting money for a dowry, or starting a small business in future. Missing work for medical or other reasons would therefore impact their ability to achieve these goals.

Participants, in general, did not report a fear of losing their jobs. They recognized that the factories were having difficulty finding workers and that there were multiple vacancies in the factories. More than $60 \%$ of the factory workers that were interviewed saw their jobs as transitory and wanted to leave the factories as soon as they had accrued enough money to find better employment. Every participant also stated that health is more important to them than money. Participants stated that they could take a medical leave if necessary, without fear of job termination.

\section{Discussion}

Based on previous research, we hypothesized that fear of job termination and pressure by management were the main barriers to female workers seeking healthcare (5-6). Through the focus group discussions and analysis, we discovered that while pressure by management was a major barrier to care, fear of job termination was not. Workers did not express fear of being fired but instead reported a high level of job security as they knew that factory workers were in high demand. They did, however, report that financial loss from missed work was a serious negative consequence and could significantly impact their costs of living and wages. 
In fact, compared to the obedient and scared "good girls" caricatured by anthropologists, the participants in this study came across as strong and independent women. They had their own personal goals and ambitions. They wanted financial independence for themselves. Most saw their jobs at the factories as means to an end, and many were seeking exit options for themselves. In certain circumstances, seeking care was just not beneficial because it would hamper the achievement of these goals. Thus, financial considerations and achieving personal goals played a major role in taking time off to seek care.

While the results did not support the study's hypothesis about workers' fear of job termination, they did show that targets and pressure set out by management were barriers to seeking healthcare. Other barriers that were discovered included a preference for healthcare outside of the factory and perceptions about healthcare. For these latter two barriers, there seems to be a disconnect between the needs and health status of the workers group, and the services provided at the factories. Each factory had a staffed clinic, but workers did not understand what the medical management could do. Doctors were available in-house but still workers preferred seeking care from outside the factories. These sorts of inefficiencies create a waste of time and resources, and poorly serve the workforce.

When looking at the overall health of the focus group participants, it is clear there is a large difference in the percentage of individuals who reported musculoskeletal pain compared to the Duke-Ruhuna study. In this study, 22 out of 24 individuals (91.7\%) reported "body pain" (musculoskeletal pain) in the month prior to the discussions. In the Duke-Ruhuna study, it was $15.5 \%$ (4). It should be noted then that the previous study defined musculoskeletal pain as occurring more than three times or lasting a week or more during the previous 12-month period. Due to this definition, the multiple number of events needed, and the long recall period may have downplayed the actual prevalence of somatic disease, however, the larger sample size $(n=1058)$ of the first study cannot be overlooked.

There are limitations to this follow-up study. The same factories and workers from the original DukeRuhuna study were unlikely to have been interviewed again in this study. Also, to protect both factories and workers, participants' factories were not disclosed. As such, information cannot be gleaned from specific well be a minority of factories that were captured in this study. Participants' productivity was also not captured in this study. This would have been ideal to correlate with other metrics not captured, such as participants' stress level and severity of illness. Further research may elucidate these relationships and assess occupational health interventions against the barriers identified.

\section{Conclusions and Recommendations}

In the Duke-Ruhuna study, there was a reluctance of female workers with musculoskeletal pain to seek care even with severe illness. The current study highlighted multiple barriers that can play into this treatment seeking pathway from financial considerations to internal and external pressures, to convenience and education.

Through these findings, we recommend changes in workplace operations and policies to create a healthier, more productive workforce. It is unlikely that production targets by factory management will be reduced, however, we believe that interventions such as introducing additional paid days for sick leave separate from annual leave and introducing forums and education about occupational health in the factories, are realistic and can make a difference. Through these action points, the industry can promote better proactive healthcare seeking behaviour among Sri Lankan female garment workers in the free trade zones.

\section{Public health implications}

The burden of musculoskeletal disease among Koggala female garment workers is a public health concern. Good functional status is the key if female workers are to remain independent and be active in their families and communities. This study identified barriers to healthcare seeking for garment workers. Health promotion and musculoskeletal prevention activities should target these barriers to prevent or delay the progress of workplace musculoskeletal injuries. This may also reduce workplace stress, improve worker wellbeing and morale, improve worker retention and reduce turnover. 


\section{Authors Declarations}

Competing interests: None of the authors of this study have any financial and non-financial competing interests to declare.

Ethics approval and consent to participate: Ethics approval by the Ethics Review Committee of the Faculty of Medicine, University of Ruhuna (ERC number 16.11.2016:3.4) and the University of British Columbia Faculty of Medicine Behavioural Research Ethics Board (ERC number H16-02839).

Funding: Private funds were used to compensate focus group participants.

Acknowledgements: We would like to acknowledge Dr Videsh Kapoor (University of British Columbia) for her support and encouragement throughout this research project. She provided invaluable advice on the planning of this project and crucial comments on numerous drafts of this paper. We are also immensely grateful for the help of Mr Nuwan Prasad Aravinda for his assistance in facilitating the focus group discussions and to Mr Nimal Rajapakse for translating and transcribing all four focus group discussions.

Author contribution: SR and FM proposed the idea and designed the study with critical inputs from TØ and VDS. TØ and VDS supervised the project. VDS coordinated the focus groups in Koggala. SR and FM led the focus groups with the assistance of an interpreter, Nuwan Prasad Aravinda. SR and FM completed the analysis of the focus group discussions and created the qualitative codebook. All authors contributed to the final manuscript.

\section{References}

1. Sivananthiran A. Promoting decent work in export processing zones (EPZs) in Sri Lanka. Geneva: International Labour Organization, 2007.

Available from: http://www.ilo.org/public/french/ dialogue/download/epzsrilanka.pdf

2. Karunaratne HD. Structural change and the state of the labour market in Sri Lanka. The Hosei University Economic Review 2007; 75(1): 179-220.

3. Sri Lankan Department of Census and Statistics. Sri Lankan Labour Force Survey: Annual Report 2016. Colombo: Government of Sri Lanka, 2016.

Available from: http://www.statistics.gov.lk/ samplesurvey/LFS_Annual\%20Report_2016.pdf

4. Lombardo SR, P de Silva V, Lipscomb HJ, Ostbye T. Musculoskeletal symptoms among female garment factory workers in Sri Lanka. International Journal of Occupational \& Environmental Health 2012; 18(3): 210-219.

Available from: https://pdfs.semanticscholar.org/ dd8b/2fde9f405355c52c8761918edf427fa55107.pdf

5. Brusser E. Labour Standards and Trade Preferences in Sri Lanka. Dialogue on globalization. Briefing papers. Sri Lanka: Friedrich Ebert Stiftung, 2005.

Available from: http://library.fes.de/pdf-files/iez/ global/50088.pdf

6. Lynch C. The "good girls" of Sri Lankan modernity: moral orders of nationalism and capitalism. Identities: Global Studies in Culture and Power 1999; 6(1): 55-89.

7. Lynch C. Juki girls, good girls: gender and cultural politics in Sri Lanka's global garment industry. Ithaca: Cornell University Press, 2007. 